\title{
Effect of bifurcation in physicochemical parameters on outburst hazard of coal seams
}

\author{
Tatyana Kiryaeva*1 \\ ${ }^{1}$ Chinakal Institute of Mining, Siberian Branch, Russian Academy of Sciences, 660091 Novosibirsk, \\ Russia
}

\begin{abstract}
The paper considers interaction between gas-kinetic and physicochemical parameters in coal seams, which conditions coal and gas outbursts. The laboratory and field test data on interaction between geomechanical and physicochemical processes in coal seams are presented for various rank of coals from Kuzbass. The areas of higher coal and methane outburst hazard feature bifurcation in porosity, moisture content and methane absorption of coal from different operating mines in the Kuznetsk, Donets and Lvov-Volyn Basins. Bifurcation consists in the alteration of gradients of these values. At the bifurcation point of these parameters, a coal-and-methane seam can generate a disturbing gasdynamic impulse sufficient for coal self-destruction. This property explains unexpected nature of coal and gas outbursts. Keywords: bifurcation, outburst hazard, coal, absorption, methane content, moisture content, porosity, volatile yield, Langmuir equation.
\end{abstract}

\section{Introduction}

The global trend of development in the mining industry internationally is the increase in production output and transition to deeper levels (often deeper than $1000 \mathrm{~m}$ below the surface) in the increasingly difficult geological and mining conditions. Expansion of the theoretical and experimental framework of nonlinear geomechanics and geophysics within the last 50 years, as well as the discovery of alternating rock mass response to dynamic impacts and nonlinear elastic pendulum waves offers new avenues of meeting the above challenges. In this context, it is required to develop the next-level integrated monitoring of geomechanical and geodynamic safety in the areas of extensive subsoil use, based on the experimental and theoretical exploration of nonlinear deformation and wave processes for quantitative testing and control of stress-strain state in rock masses of hierarchical block structure.

\section{Theory}

The scientific and methodological relevance of such studies is easy to understand in terms of the situation in the Kuznetsk Coal Basin (Kuzbass). Where, 194 coal and gas outbursts occurred in 53 coal seams between 1943 and 2004, and 11 coal and gas outbursts happened in 5 coalfields in 7 mines and 8 coal seams between 1993 and 2014 [1,2]. The statistics implies timely character of this problem. During driving gateways in Kuzbass mines in the recent 10 years, more than 110 weak gas-dynamic events (GDE) were observed. The events induced damage in coal face areas (up to tens tons of coal in volume, with high gas emission). As of January 1, 2010, 60 mines in Kuzbass operated in 144 coal seams (including 16 outburst-hazardous seams and 58 seams prone to outbursting [1]) with various physicochemical properties.

${ }^{*}$ Corresponding author: coalmetan@mail.ru 
Build-up of the theoretical background for description of gas exchange in multi-phase geological environment of complex structure under varied rock pressure and temperature [3-6] also allows analyzing response of gas component in coal seams under mining to variation in geomechanical situation in rock mass with a view to enhancing reliability of process solutions. In this regard, it is required to create scientifically sound methods for taking into account interaction between gas-kinetic and physicochemical parameters of coal seams in specific mining conditions since variability of these coal properties prevents to complete the outburst control.

In view of the qualitative improvement of instrumentation and computation abilities in the area of gas-bearing rock mass monitoring in Russia in the recent decades, it has become possible to study interaction of geomechanical behavior and physicochemical properties of the rock mass of millions cubic meters in volume.

To deal with such problems, the databases have been collected and systematized on 15600 layer intersections in 11 coalfields in Kuzbass. The databases contain data on stratigraphy of coal and methane, coal seam methane content as well as coal and gas outbursts in mines over a long period of operation (1947-2010). The databases are protected by 4 certificates of authorship as of 2018 [7-10].

\section{Results}

Adsorption and absorption processes are critical in physicochemistry of any grade coal. Coal seam methane (methane absorption) is generally calculated from the Langmuir equation:

$$
\mathrm{X}_{\mathrm{s}}=a b P /(1+b P), \mathrm{m}^{3} / \mathrm{kg}
$$

where $a$ is the limiting methane absorption, $\mathrm{m}^{3} / \mathrm{kg} ; b$ is the sorption coefficient, $1 / \mathrm{Pa} ; P$ is the gas pressure, $\mathrm{Pa}$.

Methane absorption is tightly connected with physicochemical properties and physical structure of coal substance: volatile yield, porosity, moisture content, etc. [11]. According to [12], the average rank coal is the most outburst-hazardous, and the sorption coefficients $a$ and $b$ are the functions of volatile yield. It was supposed that the coefficients were to conform with outburst hazard of major stratigraphic structures in coal basins in Russia. The supposition was tested in the analysis of change of the first-order derivative in the Langmuir equation, $G$, depending on the limiting methane absorption $a$ in terms of coal from Kuzbass as well as Donets and Lvov-Volyn Basins (starting from lignite and finishing with super anthracite) with regard to minimum values of outburst-hazardous depths from the factual mining data collected in 15 coalfields in Kuzbass:

$$
G=d X_{s} / d P=a b /(1+b P)^{2} .
$$

Theoretically, it follows from (2) that at $P=0$, there should be no point of inflexion in Fig. 2. However, it appears that for Kuzbass coal at $a=18 \cdot 10^{-3} \mathrm{~m}^{3} / \mathrm{kg}$, the $G-a$ curve contains a flex point for the coal seams described by the highest gas-dynamic activity [12]. For these seams, the outburst-hazardous depth of mining is determined as $150 \mathrm{~m}$. For coal from the Donets and Lvov-Volyn Basins, the flex point is at $a=18.5 \cdot 10^{-3} \mathrm{~m}^{3} / \mathrm{kg}$ (Fig. 1). 
(a)

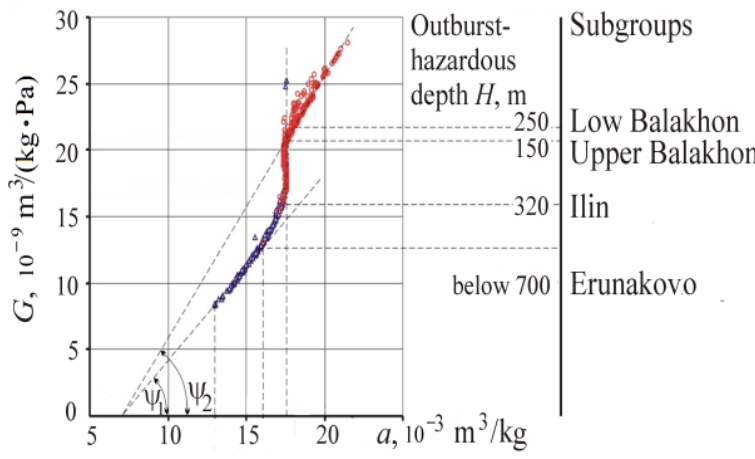

(b)

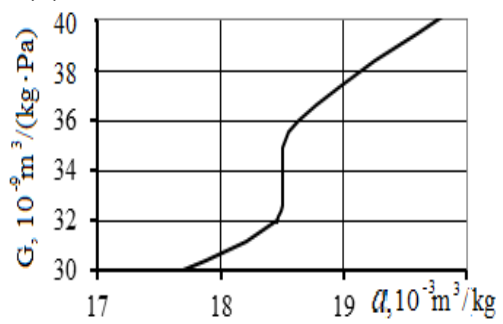

Fig. 1. Variation of the first-order derivative in the Langmuir equation versus liming methane absorption of coal from (a) Kuzbass and (b) Donets and Lvov-Volyn Basins

The detailed study of the phenomenon in terms of Kuzbass coal subseries produced the limiting methane absorption $a$ versus porosity $P$ (Fig. 2). It is seen that the plot can be divided into three branches. Furthermore, the level of $a=18 \cdot 10^{-3} \mathrm{~m}^{3} / \mathrm{kg}$ fitting the bifurcation point stands clearly out. Let us analyze the values of porosity at this level.

Porosity is important in understanding permeability and, in particular, its effect on methane absorption capacity of coal seam. With this end in view, we attempted to relate porosity and volatile yield using the catalog data on Kuzbass coal [7-10]. The obtained results are demonstrated in Fig. $2 \mathrm{~b}$ for different limiting methane absorption $a$ : 1) $a<18 \cdot 10^{-3}$ $\mathrm{m}^{3} / \mathrm{kg}$; 2) $a=18 \cdot 10^{-3} \mathrm{~m}^{3} / \mathrm{kg}$; 3) $a>18 \cdot 10^{-3} \mathrm{~m}^{3} / \mathrm{kg}$.

As the porosity decreases to $5.5-6 \%$ at the bifurcation point at $a=18 \cdot 10^{-3} \mathrm{~m}^{3} / \mathrm{kg}$ (Fig. $2 \mathrm{a}$ ), the outburst-hazard properties of coal change. When $a<18 \cdot 10^{-3} \mathrm{~m}^{3} / \mathrm{kg}$, the porosity of coal lowers with increasing volatile yield (Fig. 2b). This range of coal rank accommodates outburst-nonhazardous geologically young ( 260 million years) coal with $V^{d a f}=35-45 \%$.

At the bifurcation point at $a=18 \cdot 10^{-3} \mathrm{~m}^{3} / \mathrm{kg}$, the porosity remains nearly the same with increasing volatile yield and fits with the average coal rank which is the most outbursthazardous. This is evident in the Lower Balakhon subseries which is the oldest geologically (307 million years) and coal/gas outburst-hazardous. When $a>18 \cdot 10^{-3} \mathrm{~m}^{3} / \mathrm{kg}$, the porosity decreases in direct proportion to the volatile yield (geological age of coal is 275 million years). Thus, the highest outburst hazard is a feature of bituminous coal with porosity of 6 $\%$ and limiting methane absorption $a=18 \cdot 10^{-3} \mathrm{~m}^{3} / \mathrm{kg}$.

(a)

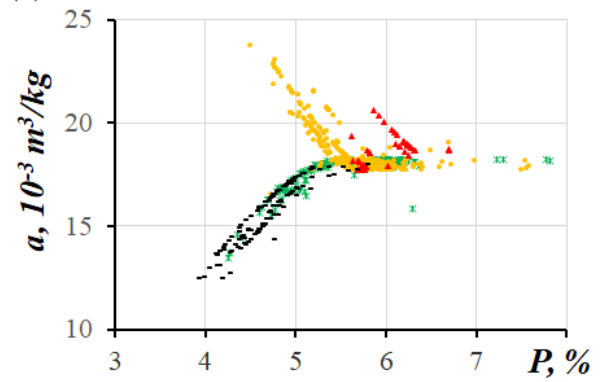

(b)

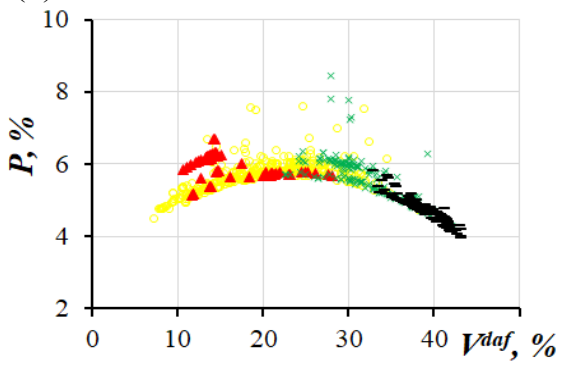


Subseries

Upper Balakhon $\times$ Ilin

$\triangle$ Lower Balakhon - Erunakovo

Fig. 2. (a) Limiting methane absorption $a$ versus porosity $\Pi$ and (b) porosity $\Pi$ versus volatile yield $V^{\text {daf }}$ for coal subseries in Kuzbass

The similar tests were carried out for the moisture content of Kuzbass coal (Fig. 3). As follows from the figure, the moisture content of the most outburst-hazardous coal subseries Lower Balakhon ranges as $1-1.3 \%$. The same range matches the bifurcation point. Coals with moisture content of 1.5-2\% belong to the Upper Balakhon series of lower outburst hazard. When coal has moisture content above $2 \%$, its limiting methane absorption decreases and so does outburst hazard in comparatively young subseries Erunakovo and Ilin.

The moisture content-volatile yield relationship shows that average rank coals have minimum moisture content (Fig. 3b). For coal seams with volatile yield less than $15 \%$, the moisture content changes by $0.5 \%$ while for coal with $V^{d a f}>30 \%$ the change in the moisture content reaches $2 \%$.

(a)

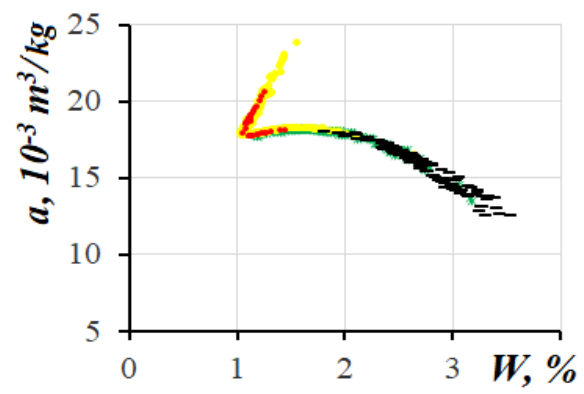

(b)

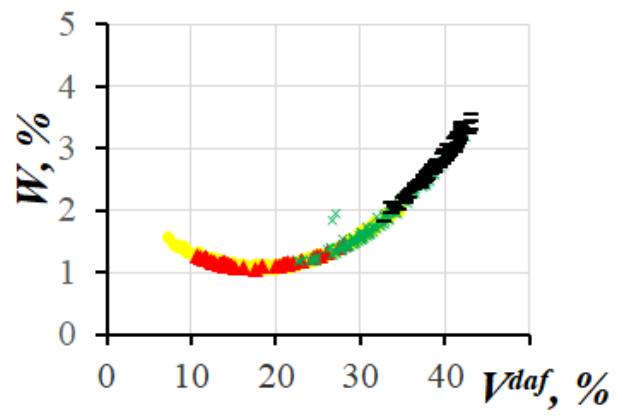

Subseries

- Upper Balakhon $\quad \times$ Ilin

$\triangle$ Lower Balakhon - Erunakovo

Fig. 3. (a) Limiting methane absorption versus moisture content and (b) moisture content versus volatile yield for coal subseries in Kuzbass

These results also prove the earlier made conclusion that the most outburst-hazardous coal seams in Kuzbass have the limiting methane absorption of $18 \cdot 10^{-3} \mathrm{~m}^{3} / \mathrm{kg}$ and moisture content of $1-1.3 \%$.

In the further analysis of the effect exerted by coal moisture content on outburst hazard, we correlated energy of relaxation of methane [12] and natural moisture content of coal. The result is demonstrated in Fig. 4 (in-line arrangement of data in the figure is due to rounding of the moisture content values when measured). 


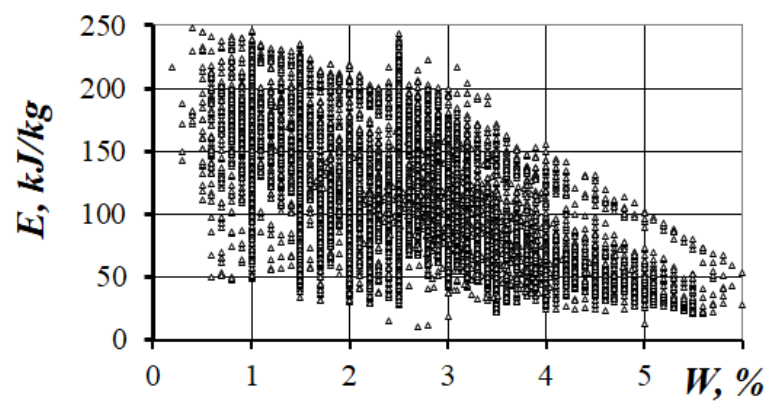

Fig. 4. Specific energy of relaxing gas versus moisture content of coal

In this way, the data on 15396 layer intersections in 11 coalfields in Kuzbass show that as the moisture content of coal decreases, the specific energy of relaxing gas lowers proportionally. The specific energy of relaxing gas equaled approx $200 \mathrm{~kJ} / \mathrm{kg}$ at the moisture content of $1 \%$ while it nearly halved at the moisture content of $3 \%$.

\section{Conclusions}

It has been found that zones of the increased coal and methane outburst hazard feature bifurcation in the values of porosity, moisture content and methane content in terms of coal under mining in the Kuznetsk, Donets and Lvov-Volyn Coal Basins. The laboratorymeasured porosity of coal samples was $6 \%$ while the analytical moisture content was $1-1.3$ $\%$. With that combination of physicochemical parameters, in accordance with catalogs [710], Kuzbass coal seams with the limiting methane absorption $\sim 18 \cdot 10^{-3} \mathrm{~m}^{3} / \mathrm{kg}$ have experienced the highest coal and gas outbursts since 1943 up to this date. Coal seams possessing the methane absorption above or under the value of $18 \cdot 10^{-3} \mathrm{~m}^{3} / \mathrm{kg}$ but the same porosity and moisture content are less outburst-hazardous (from mine practice). However, in highly productive longwalls, gas releases from broken coal in the outburst hazard mode since the initial velocity of gas recovery is high. For this reason, in-mine gas drainage is required to be implemented. At the bifurcation points of the parameters included in the Langmuir equation (at the limiting methane absorption of $18 \cdot 10^{-3} \mathrm{~m}^{3} / \mathrm{kg}$ for Kuzbass coal and $18.5 \cdot 10^{-3} \mathrm{~m}^{3} / \mathrm{kg}$ for Donets and Lvov-Volyn Basins coal), a coal seam is genetically able to generate a disturbing gas-dynamic impulse sufficient for self-destruction be initiate. These properties explain unexpected nature of coal and gas outbursts.

The research has been carried out within the framework of the Russian Science Foundation, Project No. 17-17-01282.

\section{References}

1. V.S. Zykov, Coal and Gas Outbursts and Other Gas-Dynamic Phenomena in Mines (Kemerovo, 2010) 333 pp. [in Russian].

2. Systematized Data on Coal and Gas Outbursts in Mines in the East and North of the Country (Kemerovo, 1973) 428 pp. [in Russian].

3. V.N. Oparin, T.A. Kiryaeva, A.Y. Khavkin , Int. J. Nanotechnol., 15 (4/5), 301 (2018).

4. V.V. Adushkin, V.N. Oparin, J. of Mining Science, 50 (4), 623 (2014).

5. V.N. Oparin et al. Destruction of the Earth's Crust and Self-Organization under Strong Anthropogenic Impact (Novosibirsk, 2012) 632 pp. [in Russian]. 
6. V.N. Oparin, M.A. Zhuravkov, V.P. Potapov et al. Geomechanical Fields and Processes: Experimental and Analytical Studies into Initiation and Growth Accident Sources in Geotechnical and Natural Systems (Novosibirsk, 2018, 2019), 1549 pp, 2545 pp [in Russian].

7. T.A. Kiryaeva, V.N. Oparin, RF Database Certification No. 2018620032. Stratigraphy of Coal and Methane Reserves as of January 1, 2010, (Novosibirsk, 2018).

8. T.A. Kiryaeva, V.N. Oparin, RF Database Certification No. 2018620035. Catalog of Coal Seam Methane Content in Kuzbass, (Novosibirsk, 2018).

9. T.A. Kiryaeva, V.N. Oparin, RF Database Certification No. 2018620036. Catalog of Coal and Gas Outbursts in Kuzbass, (Novosibirsk, 2018).

10. T.A. Kiryaeva, V.N. Oparin, RF Database Certification No. 2018620264. Catalog of Methane Absorption Capacity of Kuzbass Coals, (Novosibirsk, 2018).

11. V.N. Oparin. J. of Mining Science, 53(2), 201 (2017).

12. T.A. Kiryaeva, Estestv. Tekhnich. Nauki, 4, 309 (2011).

13. A.T. Zhou, K. Wang, V.N. Oparin, J. of Mining Science, 53(3), 533 (2017).

14. Zuzana Weishauptová, Oldr`ich Pr`ibyl, Ivana Sy’korová, Vladimír Machovič, Fuel, 139, 115 (2015).

15. A. Kiani, R. Sakurovs, M. Grigore, A. Sokolova, Int. J. of Coal Geology, 200, 77 (2018).

16. R. Sakurovs, L. Koval, M. Grigore, A. Sokolova, L.F. Ruppert, Y.B. Melnichenko, Int. J. of Coal Geology, 186, 126 (2018).

17. G. Staib, R. Sakurovs, E. Gray, Fuel, 143, 612 (2015). 